\title{
Consequences of Enduring Low Fertility - A German Case Study Demographic Projections and Implications for Different Policy Fields
}

\author{
Martin Bujard
}

\begin{abstract}
Compared to all other countries in the world, Germany has been a "lowfertility country" for a longer period: the total fertility rate has been below 1.5 for four decades. Being the first to experience this development, a case study of Germany allows analysing the consequences of an enduring birth decline. In Germany, low fertility is also an increasingly big issue in politics as well as science, especially due to its extensive consequences on several policy fields that already become visible. However, the assessment of the consequences differs tremendously when it comes either to its intensity or to the question whether ageing or rather population decline is the more severe problem. Differentiated by these two processes, this article combines demographic analysis with the assessment of the consequences for different policy fields such as pensions, health, the economy, the labour market, culture, the EU, international relations and the party system.

For all these policy fields, the consequences are serious, and partly ambivalent but overall negative. The occurrence of the consequences and the different policy options how to deal with these consequences differ considerably between the policy fields. Ageing is a more severe problem than shrinking, because the severe changes in the age structure in the social security system that will take place until 2040 apply to most Germans and are inevitable. On the other hand, the population decline can still be avoided demographically and does not affect all inhabitants negatively. Regarding the consequences of a declining population, one has to differentiate between an individual and a national perspective. National consequences are rather negative due to a decline of international influence and power, especially within the European Union. The study also demonstrates that the long-term consequences of enduring low fertility are not necessarily negative for political competition, the culture, the labour market and the economy, if appropriate political action is taken. The analysis also identifies possible future demographic and political parameters. Thus, this case study is relevant for other low-fertility countries, which will have to face similar demographic processes in the future.
\end{abstract}

Keywords: Low fertility · Ageing · Welfare state $\cdot$ Population decline $\cdot$ European Union 


\section{Introduction}

In 2012, there have already been 29 "low-fertility countries" worldwide (World Bank 2014), being defined as having a total fertility rate (TFR) of less than 1.5. Most of these 29 countries have however only been affected by this phenomenon for one or two decades. Compared to all other countries in the world, the Federal Republic of Germany has been a low-fertility country for a longer period, in fact, for four decades. ${ }^{1}$ Despite Germany, other countries also exhibited a continuously low TFR such as Italy since 1984, Spain since 1988, and Japan, Bulgaria and Romania since 1993. The case of Germany is especially interesting for the analysis of the long-term impact of an enduring low fertility since a second generation is already affected by this phenomenon. This leads to the situation that consequences are already clearly visible and a large number of analyses are available from different disciplines. The following case study analyses the impact of the enduring low fertility in Germany. Despite several specifically German contexts, the findings are relevant for many other countries as they are facing similar challenges, albeit delayed.

The enduring low fertility and the demographic change are receiving a massive amount of attention in politics, the media and the scientific community in Germany. (cf. Barlösius/Schiek 2007; Stock et al. 2012). There is even talk now of "demography policy" as constituting a separate policy area (Hüther/Naegele 2013; Mayer 2012). This big issue has also arrived in politics: the German Federal Government commissioned a Demography Report (BMI [Federal Ministry of the Interior] 2012) and developed a Demography Strategy (BMI 2013). Federal Chancellor Angela Merke/ is placing demographic change on the same level as globalisation (Merke/ 2012). The fact that many policy areas are directly affected by demographic change is shown not lastly by the cooperation of almost all the Federal Ministries in establishing the Federal Government's Demography Strategy as well as the presence of eight Federal Ministers and of the Federal Chancellor at the first two "Demography Summits", which were held in 2012 and 2013.

"Demographic change, along with globalisation, probably constitutes the greatest change in our society, but also in the personal life of each individual, in the first half of the 21st Century." (Merke/ 2012; translated by CPoS)

In view of this significance, it is astonishing how very different the assessments of the impact of the low fertility in Germany are. Whilst Birg (2003: 14) sees the "demographic demise of Germany" which could be a "herald of our country departing from its thousand-year history", Hondrich (2007: 1) considers the low fertility "a blessing for our society" (quotations translated by CPoS). These two quotes provide examples of the enormous range of assessments. The polarisation between "apocalyptic scenarios" and "downplaying" is characteristic of the debate on low fertility in politics, the media and the scientific community in Germany.

1 The TFR was 1.45 in 1975, and has remained below 1.5 since then, ranging at values between 1.24 and 1.45 (Statistisches Bundesamt 2013a). 
How did this come about? There is a multitude of impacts for society, industry and politics which need to be considered in order to reach an overall evaluation. The individual aspects have been analysed extensively, but no consistent distinction is made in most cases between the two demographic consequences of low fertility - ageing ${ }^{2}$ and shrinking of the population. This is, however, necessary in analytical terms. The assessments found in current literature also diverge fundamentally when it comes to the question of whether it is the impact of ageing or of the shrinking process that will be more severe.

Moreover, demographic projections need to be taken into account and their assumptions also need to be appropriately assessed. Analyses are frequently fragmented, with demographic analyses of the impacts on one side and, on the other, analyses from a social or political science perspective. These circumstances make it more difficult to systematically assess the different impacts of low fertility plotted against demographic factors, and also to come to a scientific overall evaluation. This might also be the case why demographic misinterpretations, questionable assumptions or particular views often dominate the assessment of the phenomenon of low fertility.

This article analyses the impact of enduring low fertility in Germany for various policy areas such as pensions, health, the economy, the labour market, international relations and the EU, as well as the society and party competition. To this end, a systematic link is created between demographic processes on the one hand (Section 3-4) and the political, societal and economic consequences on the other (Section 5-6). Based on this link, a synthesis of the consequences of low fertility is developed which offers answers to three questions: Which impact does the German low fertility have on different policy areas - and when does it happen exactly? What kind of political and demographic adjustments will be possible in future? As well as: Are greater problems caused by ageing or by shrinking? Finally, the validity of the findings for other countries will be discussed.

\section{The state of research and analysis strategy}

\subsection{Current state of research}

The second fertility decline, which started in Europe in the mid-1960s, forms part of the second demographic transition (van de Kaa 1987). It is distinguished in demography as a separate phenomenon compared to the first demographic transition, which was accompanied by a considerable decline in child mortality and lasted in Germany from 1870 to 1930 . As a result of the second fertility decline, the total fertility rate (TFR) has settled at 1.2 to 1.5 in Germany and some Southern European and East Asian countries, whilst other industrialised countries in Northern Eu-

2 The term "ageing" is used here for the shift in the age structure according to which the share of elderly people in the population increases considerably. 
rope, North America or France have a TFR that is close to the replacement rate of 2.1 (OECD 2014). In many countries, the TFR is influenced by the increasing age of women at first birth, and the TFR is lower than the final number of children of the respective cohorts (Bongaarts 2001). In Germany, the TFR has been ranging between 1.24 and 1.45 since 1975, and hence has been one-third below the replacement level for more than a generation (on the causes cf. Bujard et al. 2012). This is the longest phase of such a low fertility level ever recorded in the world.

When analysing the consequences of this enduring low fertility, one needs to distinguish between ageing and shrinking in analytical terms (e.g. Swiaczny 2014). Both imply a highly diverging impact. The assessment of the consequences of the enduring low fertility in Germany varies in the literature with regard to whether it is ageing (Sinn 2013) or the population decline (Birg 2003; Kaufmann 2005) which is the "worse" development. When it comes to population projections, the influence of the three major indicators - life expectancy, the migration balance and the birth rate -vary fundamentally with regard to ageing and shrinking.

Population projections which include projections both for the size of the population and for ageing are available for example from the United Nations for the period up to 2100 (UN 2012), as well as from the Federal Statistical Office (Statistisches Bundesamt 2009a/b) for Germany up to 2060. Trends observed so far from demographic indicators are extrapolated, and different models are calculated for different assumptions as well as for different combinations of assumptions. These projections are explicitly not understood as predictions, but the medium variants are nonetheless frequently interpreted as such. It is nonetheless necessary to point to two criticisms of these projections: Firstly, the influence of the presumed average age at childbirth on the fertility level is not taken into account in some cases (Goldstein et al. 2011), and this may lead to the subsequent underestimation of the TFR in the medium variant of the forecast of the Federal Statistical Office (Statistisches Bundesamt 2009a) given that the age at childbirth ceases to rise from 2020 onwards. Secondly, probabilistic approaches criticise the deterministic nature of classical projections and the fact that uncertainty is reproduced by different variants, and that it is not quantified using confidence intervals (values for Germany see: Scherbov et al. 2008: 40-41). However, probabilistic approaches cannot predict the probability of regime collapse or future developments in the assumptions. The demographic analyses in Sections 3 and 4 are based on the population projections of the Federal Statistical Office since they are dominant in Germany.

The literature on the consequences of the population decline as well as population ageing with regard to social systems, the industry, the society, the EU, international relations and competition between political parties is extensive. Since current research frequently focuses on individual consequences, we will not give an overview of the literature review, but rather refer to the state of research at respective places in Sections 5 and 6. 


\subsection{Analysis strategy}

In order to analyse the consequences of the enduring low fertility for a specific policy area, it is necessary to link demographic and political science perspectives. Since the low fertility manifests itself in two different demographic phenomena, namely ageing and shrinking, these two processes are each discussed using different projections. Here, the respective dynamics and time frames, as well as their likelihood of being influenced, are outlined by the three demographic indicators of births, migration and life expectancy (see Fig. 1). Analysing the demographic processes is necessary in order to understand what influence is exerted by the enduring low fertility for instance on the social security systems at what time and with what probability. Moreover, it is not sufficient to only look at a specific projection value for a single year, but it is rather essential to understand the processes and possible adjustments to it.

Next, the impact of the low fertility on individual policy areas is analysed, focussing on some central consequences. The consistent distinction of ageing and shrinking is retained throughout the paper. The impact of ageing on the social systems, the industry, society and party democracy will be discussed using the different projections. The impact of the population decline is then analysed with regard to international relations, the EU, the economy, the environment and society, particularly in comparison to other industrialised countries. This analysis therefore makes it possible to evaluate which consequences can be regarded as negative, which as positive and which cannot be categorised in this dichotomy.

Because of the dynamics of demographic processes, the aspect of time is vital to the evaluation of the impacts. These impacts occur many decades after the manifestation of low fertility, whilst ageing processes and the population decline

Fig. 1: Consequences of an enduring low fertility

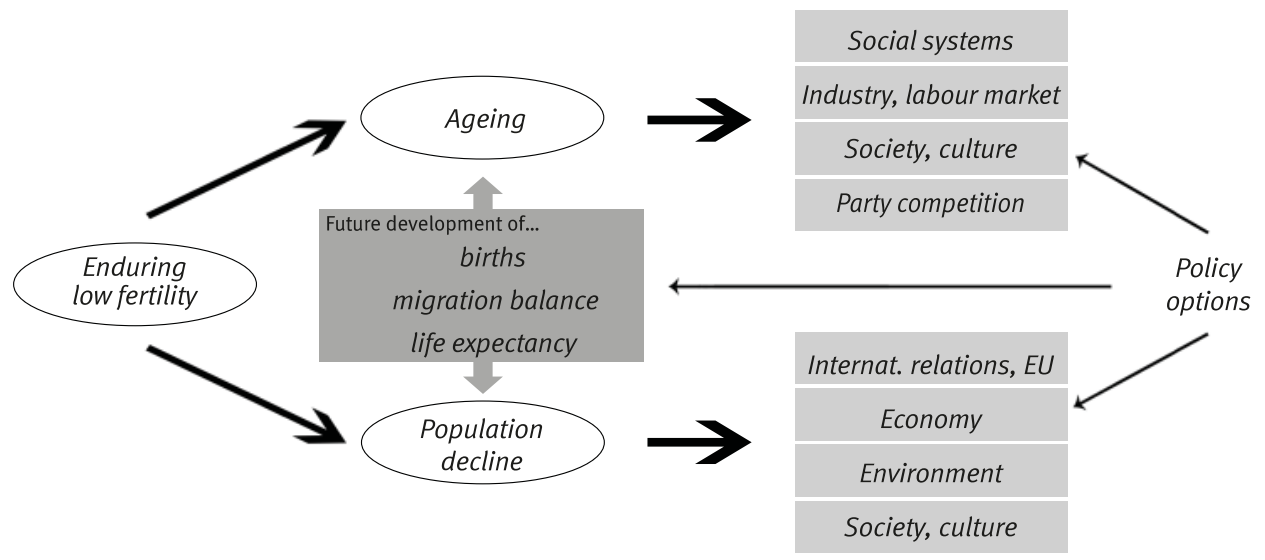

Source: Own design 
are based on differing dynamics and a different climax in the consequences. In this context it is of major importance whether the projections refer to the period up to 2030,2060 or even 2100 . Since projections become less certain as the period stretches, whilst on the other hand the demographic momentum makes long-term calculations possible, we explore the question of up to which year it makes sense to interpret them and which uncertainties have to be taken into account.

The demographic analysis is then combined with a political science approach. There remain two fundamentally different types of policy options with regard to the consequences of the enduring low fertility: to influence the demographic indicators such as future fertility rates and migration, as well as to adjust responses of the individual policy areas to the consequences. The respective policy options are analysed here, thus establishing a basis for demographic policy advice.

These steps allow a final judgment regarding the two controversies mentioned above: Firstly, on the question of the overall evaluation of the phenomenon, and secondly whether ageing or rather the population decline is more severe for society.

\section{$3 \quad$ Ageing}

The ageing of the population is not only caused by the low fertility, but it is amplified by the increase in life expectancy. The differences in age structures between the industrialised countries are largely caused by the low fertility, given that the fertility development varies much more widely between the countries than does the trend in increasing life expectancy. The ageing process can be quantified through frequency measures and age dependency ratios. For instance, the median age is relevant to the impact of ageing on the electoral system, whilst the age dependency ratio is decisive for the social insurance systems.

\subsection{Median age}

The median age in Germany increased from 35 in 1950 to 43 in 2009, and will rise to about 52 years between 2045 and 2060. The median age of voters is more authoritative when it comes to the assertion of changes in the relative strength of parties: It was quite constant in the second half of the 20th Century with 44.4 years in 1950, 44.7 in 1970, 45.0 in 1990 and 46.4 in 2000. Reaching 50.1 in 2012, the median voter age increased to over 50 years for the first time.

Figure 2 shows the median voter age up to 2060 which was calculated using the medium variant (lower limit) of the 12th coordinated population projection (Statistisches Bundesamt 2009b). Accordingly, it will increase to 55.4 years by 2030 (cf. Sánchez Gassen 2015: 248) and to 58 years by 2060. The main increase will be registered between 2000 and 2030 . Whilst half of the voters were aged under 45 years until the 1990s, half will be aged over 55 from 2026 onwards, and will therefore be of retirement age or shortly below. 
Fig. 2: Median age of the total population and of voters

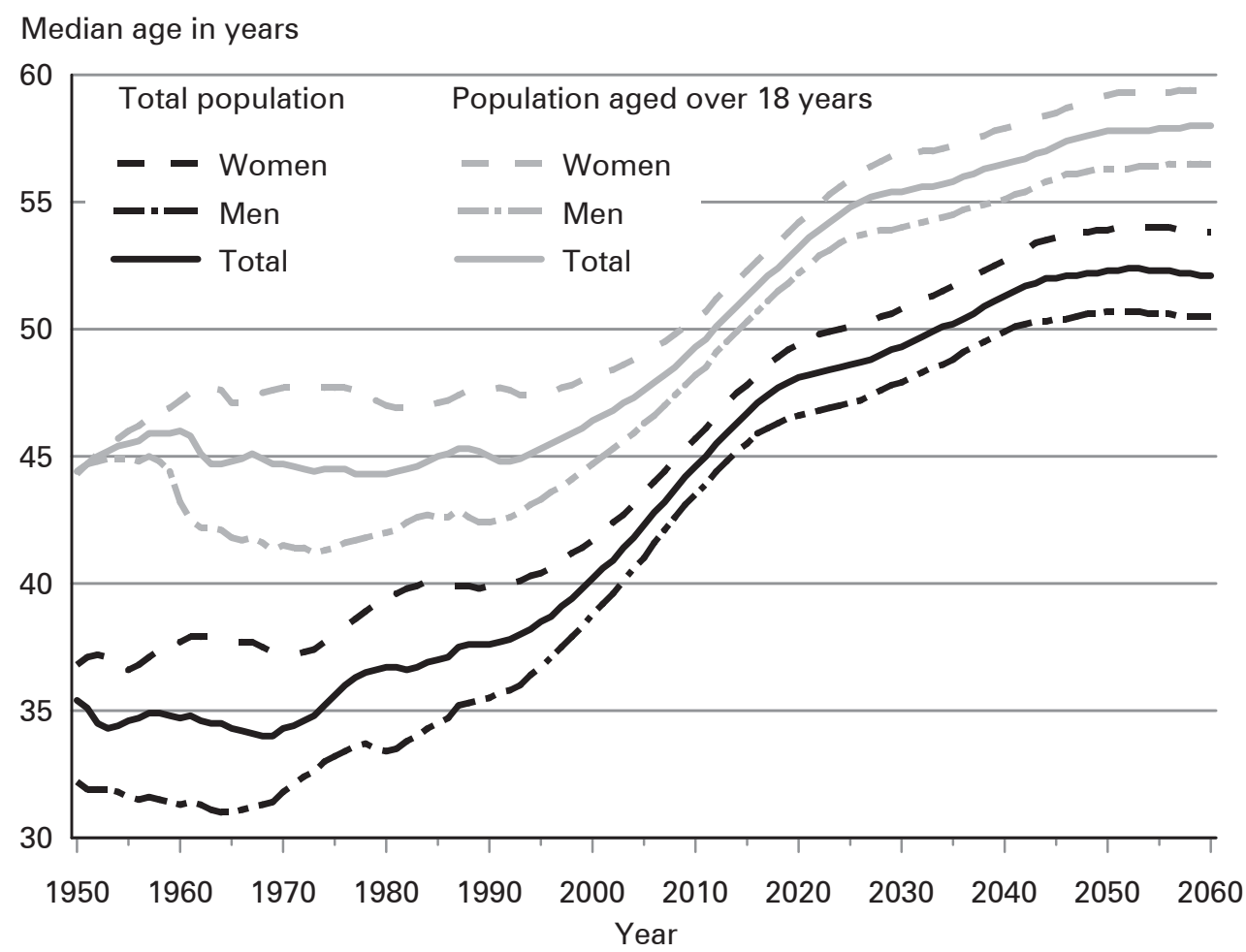

Notes: From 2012: Results of the 12th coordinated population projection, variant 1-W1 (for assumptions see Figure 3). The analysed population aged 18 and older is not identical to voters since it also includes those foreigners who are not eligible to vote. Since the age structure among Germans is somewhat older, the median voter age is slightly higher. Calculations for 2011 show that this effect accounts for slightly less than one year (0.9 years).

Source: Statistisches Bundesamt 2009b. Own calculation together with Harun Sulak

\subsection{Age dependency ratio}

The age dependency ratio is a central measure for pay-as-you-go social insurance; it relates the ratio of people who are of retirement age to those who are of working age. The age dependency ratio used here refers to the ratio of those aged 65 years and older to those aged 20 to 64 years. The largest share of increase in the age ratio takes place between 2010 and 2040. Within this period, the cohorts with low birth numbers will enter the labour market. This effect will be further amplified by the next generation, which registered even lower birth rates, as it will be by the so called baby boomer generation reaching retirement age between 2020 and 2030. Figure 3 shows the projection spectrum of the Federal Statistical Office (Statistisches Bundesamt 2009a/b). Results of the new German census, which have 
Fig. 3: Development of the age dependency ratio on the basis of different assumptions

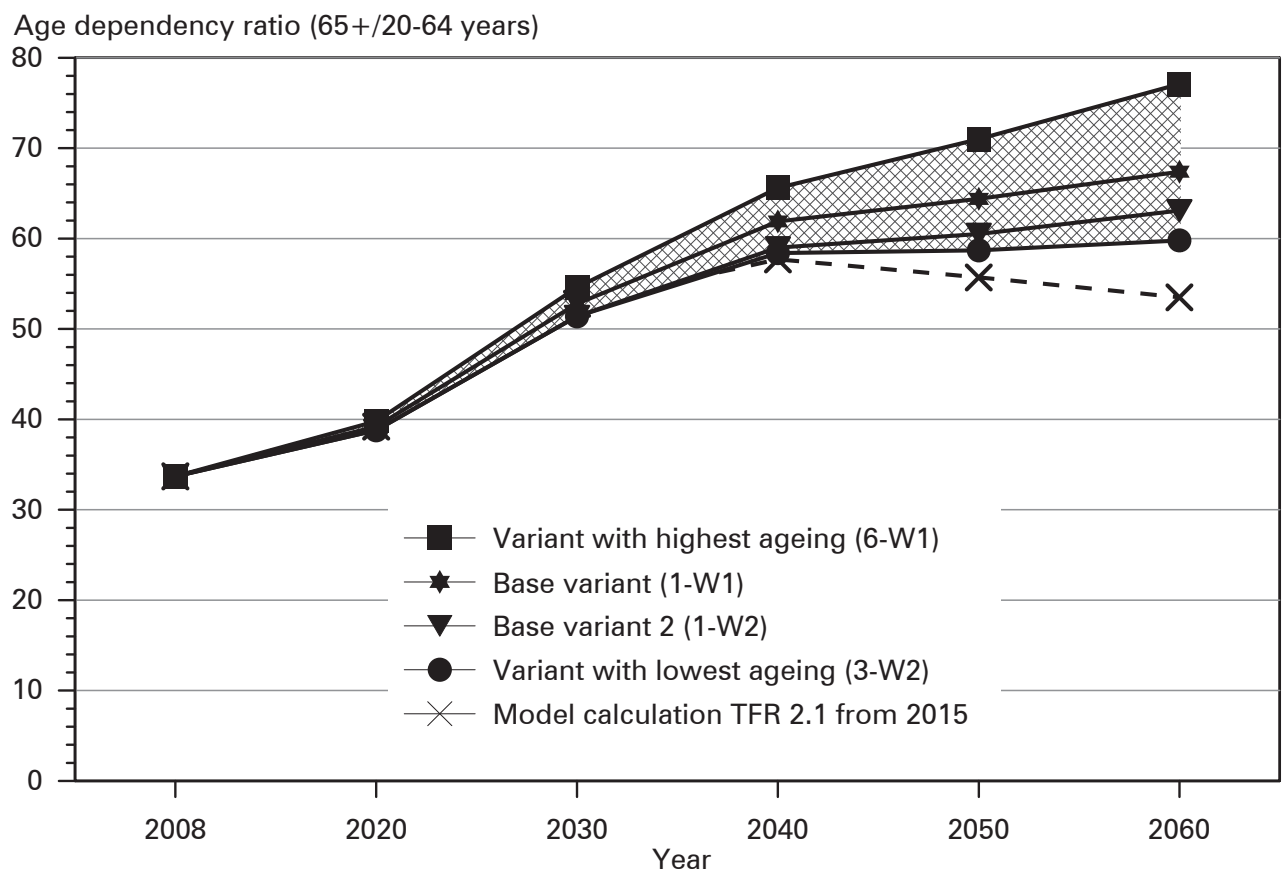

Notes: Assumptions of the base variant (1-W1): long-term annual migration balance of 100,000, life expectancy 206085.0 and 89.2, respectively; TFR 1.4. base variant 2 (1-W2): long-term migration balance of 200,000, otherwise unchanged. Variant with the highest ageing (6-W1): TFR 1.2, long-term migration balance of 100,000, life expectancy 87.7 and 91.2 , respectively. Variant with the lowest ageing (3-W2): TFR 1.6, long-term migration balance of 200,000 , life expectancy 85.0 and 89.2 , respectively.

Source: Own design based on Statistisches Bundesamt 2009b

not yet been taken into account in current population projections only marginally alter the age dependency ratios. The spectrum of the basic medium variant shows age dependency ratios of 63.1 and 67.4 for 2060 which on the basis of 2008 corresponds to an increase by 87 percent and 100 percent, respectively. The doubling of the current age dependency ratio is already reached in 2040 with values around 60; afterwards the increase slows down.

The shaded area of Figure 3 shows the progressions of the highest and lowest combinations of assumptions regarding migration, birth rate and life expectancy within the twelve different variants that have been calculated and which are regarded as realistic. In the variant with the highest ageing, the age dependency ratio reaches 65.6 in 2040, and increases to 77.1 by 2060. The variant with the lowest ageing, consequently the variant with the youngest age structure, shows a similar development until 2040 reaching 58.4, but remains constant after that (2060: 59.8). 
Whilst the share of people aged 65 years and older doubles by 2040, the share of the very old (aged 80 years and older) increases even more because of rising life expectancy. On the basis of the medium projection variant (Statistisches Bundesamt 2009a), it is assumed for Germany that the share of the very old will almost triple, from roughly 5 percent (4 million) in 2008, to 14 percent (9.05-9.23 million) by 2060 .

\subsection{The influence of future migration and fertility on ageing}

That an increased immigration can only have a minor effect on ageing is clearly shown by the much-cited model calculation of the United Nations (UN 2000), according to which Germany would need an exorbitant amount of immigration, namely 188 million people by 2050 , in order to maintain the age dependency ratio at a constant level. Immigrants and their somewhat higher fertility do have an impact on the labour market and on the age structure (Sobotka 2008), but later in life they also become old, and their fertility frequently tends to resemble that of Germans (Birg 2003).

The influence of migration on ageing will be quantified below: If the annual migration balance is around 100,000, the age dependency ratio will be 67.4 by 2060 according to the medium projection. If immigration is twice as high for every year until 2060 with all other conditions remaining unchanged, the age dependency ratio would be 63.1. After more than 50 years with a migration balance twice as high, the age dependency ratio would only have fallen by 6.8 percent.

Though the fertility development of the past five decades has contributed to the ageing process, a sudden increase in the fertility rate would have little effect on ageing in the short and medium term. It is the number of births and less the fertility rate that is important for the age structure. The number of potential mothers by 2030 depends on the number of girls born in recent years. Since a succession of generations takes roughly 30 years and it takes another 20 years until working age is reached, the impact of future fertility development on the age dependency ratios is relatively minor for the next 50 years.

Even if the TFR increases from roughly 1.4 to 1.6 - which means roughly 96,000 additional births per year - the age dependency ratio would only fall from 67.4 to 63.6 by 2060 . Half a century with a much higher fertility rate would thus only reduce the age dependency ratio by 6 percent. If the TFR increases to 2.1 - the replacement level - the age dependency ratio would remain virtually unchanged until 2040. Between 2040 and 2060, it would, however, no longer increase, but would slightly fall to 53.5 (cf. Fig. 3). This would relieve the burden on the social systems from 2040 onwards. Compared with the base variant (TFR 1.4), the age dependency ratio would decline by 26.0 percent until 2060 , so that the contribution rates could be reduced by about a quarter (or pensions could be increased accordingly). 


\subsection{The (lack of) certainty of projections on ageing}

Because of demographic momentum, the precision of demographic projections for 2040 is very high, and for 2060, it is relatively high. Even with quite different assumptions, the age dependency ratio only ranges between 58 and 66 by 2040. It will increase up to 2060 in all of the 12 projections, ranging between 60 and 77 . Speaking of absolute figures, the number of people aged over 64 years will be between 21.975 million and 25.123 million. If fertility remains low, the age dependency ratio will however no longer rise as drastically as between 2010 and 2040 since, by then, the net reproduction rates will have been constantly low for as long as a human lifetime. However, a considerable increase in the TFR to 2.1 could reduce the age dependency ratio to 53.5 by 2060 , and then bring about a further reduction in ensuing years.

It can be regarded as being certain that the ageing process that has been caused to a considerable degree by the second fertility decline will lead to a doubling in the age dependency ratio by 2040, to a tripling of the share of the very old by 2050 and to an increase of the median voter age above 55 years. It is very likely that all three indicators of ageing will be roughly at this level by 2060; whether and how rapidly they continue to increase will depend on the future development of fertility, life expectancy and migration.

\section{$4 \quad$ Population decline}

Population decline is the second demographic consequence of the enduring low fertility. Fertility below replacement level results in net replacement figures below 1. Since this has been the case in Germany for many decades now, it led to a low population momentum (cf. Blue/Espenshade 2011). This momentum understood as the age structure is responsible for shrinking processes that will persist for many years even if the TFR rises. Unlike the effect of ageing, migration and rising life expectancy slow down the population decline. The dynamics over time also differ fundamentally given an enduring low fertility level: Unlike ageing, shrinking first begins gradually and increases exponentially from 2050 onwards.

\subsection{Projections of the population size by 2060}

The grey hatched area of Figure 4 shows the spectrum of the twelve scenarios which the Federal Statistical Office (Statistisches Bundesamt 2009a) considers to be realistic. The dashed line above the scenarios is based on a model calculation with a TFR of 2.1, which was considered to be unrealistic.

In the base variant (TFR 1.4; life expectancy 85.0 and 89.2 ; migration balance $100,000)$, the population decreases by 4.2 million from 2010 to 2030 , by 7.7 million up to 2040 , by 12.1 million up to 2050 and by 16.9 million up to 2060 . The German population would then have 64.651 million residents by 2060 - a decline by 20.7 percent within 50 years. The population decline would be much less pronounced in base variant 2, in which the long-term annual migration balance is around 200,000 . 
Fig. 4: Development of the German population size on the basis of different assumptions

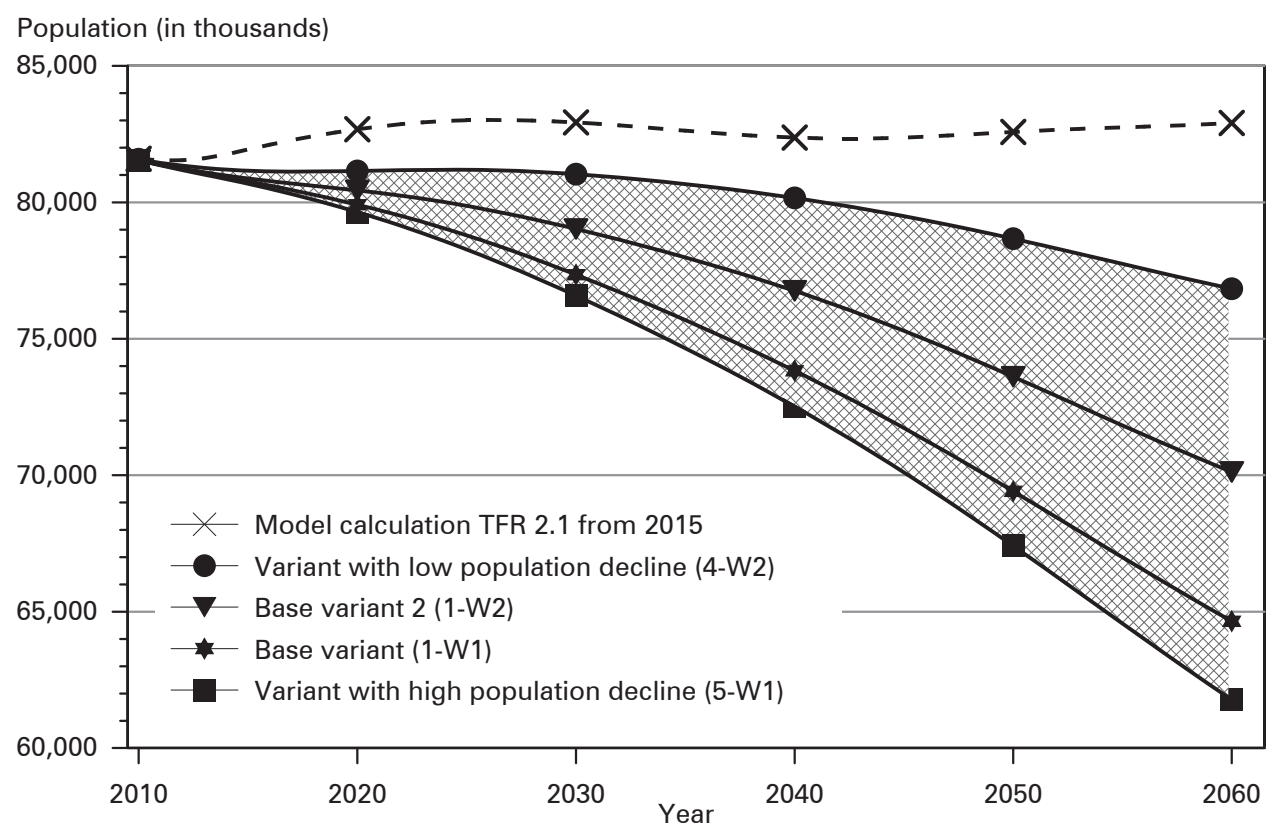

Note: Assumptions of the base variant see Fig. 3

Source: Own design based on Statistisches Bundesamt 2009b

Germany would then have 70.120 million residents in 2060, corresponding to a decrease by 11.4 million, or 14 percent. Both scenarios are similarly conceivable and realistic, but it is difficult to project the long-term development. If one takes all 12 variants into account, the population size will be between 76.6 and 81.0 million in 2030, and between 61.8 and 76.8 million in 2060. The range between the different projections is considerable: In one case, the decline is minimal, namely 5.9 percent, over a long period of 50 years, whilst in the other case it is $\mathbf{2 4 . 2}$ percent, signifying an enormous population decline.

The population development at the regional level is, however, decisive for people's respective living conditions. There are contrary developments on the regional level, and even today it is evident that there are regions which are growing as well as regions which are shrinking. Because of the advancing internal migration, in combination with the amplification of the demographic process which comes about when young people move at the beginning of their working lives, some regions will tend to become depopulated (cf. Kühntopf/Stedtfeld 2012). Since this aspect of demographic change is not primarily caused by the fertility decline, it will not be discussed here any further. 


\subsection{The influence of future migration and fertility on the shrinking process}

The size of the population by 2060 will be influenced by today's age structure and the future development of three indicators: fertility rate, migration and life expectancy. There is no doubt that the life expectancy will continue to rise; the influence of different scenarios on the size of the population is however minor. Effects of migration and the fertility rate are, however, different:

The effect of migration on population shrinking can be quantified: According to the base projection, Germany's population size would be 64.7 million by 2060 , assuming an annual migration balance of 100,000 people from 2014 onwards. Assuming immigration figures twice as high in each year from 2020 up to 2060, Germany would have 70.1 million residents. 100,000 additional migrants per year consequently reduce the population shrinking by roughly one-third. The shrinking process could be completely averted until 2060 if even higher immigration figures of roughly estimated 400,000 per year are achieved.

The assumption of a permanent immigration balance of 100,000 or even 200,000 people per year needs to be briefly discussed: This level of immigration from 2015 to 2060 would, when cumulated, account for a balance of 4.6 or 9.2 million people. Since emigrants must be deducted from immigrants in order to calculate the balance, total immigration would in fact be much higher. This fact gives rise to the question of typical countries of origin of possible migrants. Historically, the balance between 1950 and 2012 averaged 168,863 (own calculation based on Statistisches Bundesamt 2013b), but the development was highly volatile, and was affected by specific historic constellations such as the immigration of millions of (late) repatriates or the EU enlargement. Since the TFR is now also below the replacement level in most classical countries of origin, a high level of permanent immigration would increasingly have to come from non-European countries. This would exacerbate the political and societal demands on the integration and recruitment of qualified immigrants.

Now let us turn to the effect of the fertility rate: If the TFR were to be 1.6 from 2025 onwards, instead of 1.4, the projection for 2060 amounts to 68.8 instead of 64.7 million residents. The increase in the TFR by 0.2 over a period of 35 years would account for 4.1 million additional residents. Combining the mentioned effects of migration and fertility rate, and assuming a somewhat more optimistic life expectancy, the impact would be amplified, so that the shrinking occurring up to 2060 would be only minor with 76.8 million.

The long-term effect of the TFR on the population size is also huge with today's age structure. Given certain apocalyptic and fatalistic projections (inter alia Birg 2003), the result may be surprising: If the TFR permanently increases to 2.1 , the population size would exceed the 83 million threshold between 2025 and 2027 and oscillate in the narrow range of 82 and 83 million from 2028-2060. For this estimation, we used the basic assumptions of an increasing life expectancy ( 85.0 and 89.2 years, respectively) and a migration balance of 100,000 . The dynamics and the future compensation potential of demographic developments fundamentally dif- 
fer from ageing: The population decline is also completely avertable today if the birth rate increases to the replacement level. The later this takes place, however, the greater the immediate population decline.

\subsection{The dynamics of the shrinking process}

Model calculations up to 2100 are helpful in order to portray the exponential character of the population decline and to categorise the impact of enduring low fertility. These, however, entail considerable uncertainties, not only because of the longer time horizon of the projection, but also because it is difficult to estimate the actual size of the migration balance as well as the TFR which both exerts a greater influence on the projections than in the case of ageing. The dynamics of the shrinking process can be made clear by a hypothetical example: Without immigration, and if the TFR remains low, each generation would shrink by roughly 35 percent, this shrinking spiral accelerating from generation to generation.

This would be an exciting phenomenon in terms of evolution biology, because persisting sub-replacement fertility is historically without precedence. But it is based on two permanent assumptions which need to be discussed: The assumption that the immigration balance will not be positive corresponds neither to the historic development of Germany, nor to the relative attractiveness of Germany for migrants. Second, the following reasons might object the assumption of an enduring low fertility in the future:

- the fact that the distorting effect of the timing of births on the TFR will decrease at some point (Bongaarts 2001),

- the intergenerational relation of fertility behaviour, according to which childless lifestyles are less likely to be reproduced (Kolk et al. 2014),

- the long-term impact of family policy measures on fertility in an international comparison (Bujard 2011),

- expert assessments suggesting on average a TFR of 1.57 and 1.58 in 2030 and 2050 (Basten et al. 2013: 68).

The latest UN projections (UN 2012) include a variant where the average TFR is constantly extrapolated to 2100 (Fig. 5). Accordingly, France and the United Kingdom would already overtake Germany in the first half of the 21st Century when it comes to the size of the population. Since it will be at a similar level in all three countries (69.0-72.9 million) by 2050, slight changes in the migration balance or in the fertility development could reverse the ranking of the countries. Turkey would equal Germany by 2020 with 81.2 million residents, and it would be roughly onehalf larger by 2050 with 103.4 million residents. According to this model calculation, with 122.1 million residents Turkey would be much bigger in 2100 than EU countries such as France (77.8), the United Kingdom (75.1), Germany (43.4), Italy (39) or Spain (30.6). With regard to the historic dimension, we find that a population decline of 
Fig. 5: Population projections for 2050 and 2100

Population (in millions)

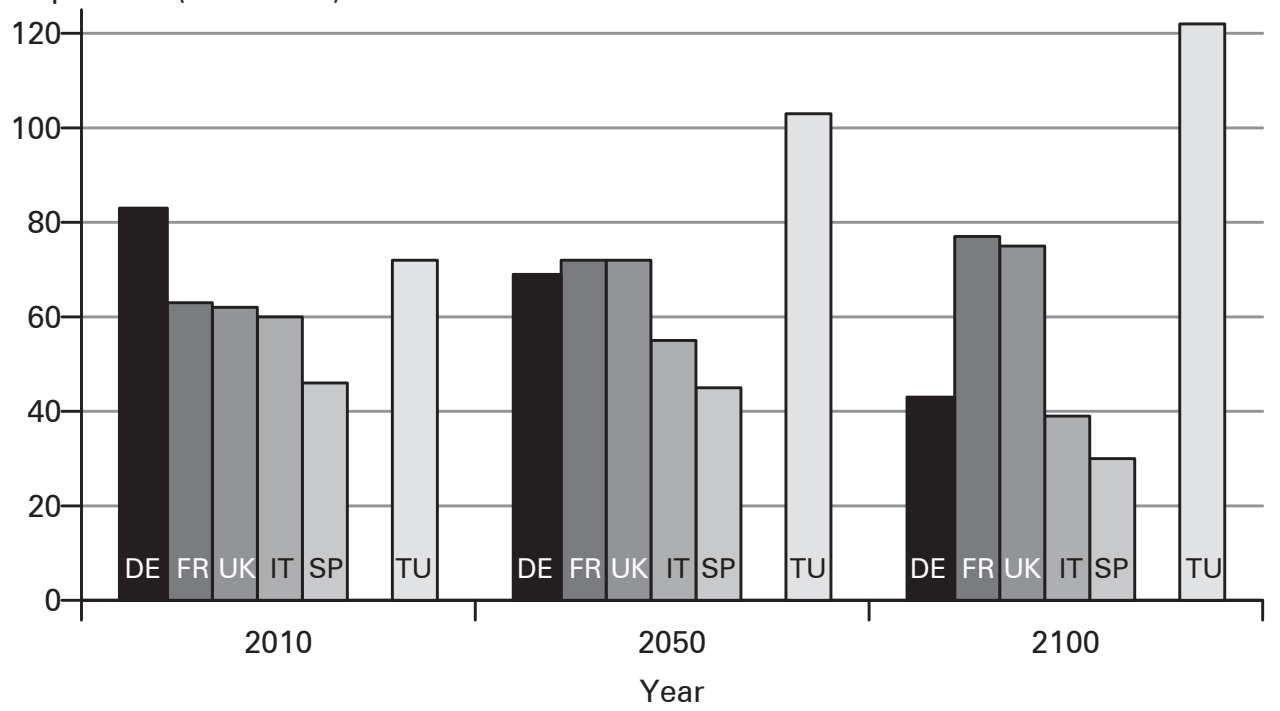

Source: Own design, data based on: UN (2012)

this nature would be an entirely new phenomenon in world history. ${ }^{3}$ The US tells a different story: Because of its stationary TFR and a positive migration balance, its population (491.5 million by 2100 ) would then be 11 times that of Germany.

No one knows whether this scenario will come true. The question is whether the fertility rate in Germany will recover. A shrinking process is however already inevitable due to the current age structure: Although France and Turkey have fewer residents today, their absolute number of births is much higher than in Germany. Therefore, it is already certain today that in 30 years from now there will be more women of child-bearing-age in both countries. The structural population decline in Germany has still been concealed by immigration in recent years: For instance, the birth deficit was 196,038 in 2012 (673,544 live births - 869.582 deaths), but as a result of the high immigration balance of 368,945 , caused by the high rate of unemployment in many EU countries, the population actually grew by 172,907 . In years without a large immigration surplus, such as 2006-2009, the population declines each year by the amount of the birth deficit. Without immigration, Germany is currently shrinking, by roughly 200,000 people each year. This trend will continue and will increase in the coming years. According to the base variant (1-W1), the birth deficit will exceed the threshold of 300,000 from 2021 onwards, the 400,000 threshold from 2029, the 500,000 threshold from 2041 and it will then settle between 500,000 and 600,000 . The population size will decline in each year from 2041 onwards by the

3 Historic population declines are usually caused by wars or epidemics (such as the Plague). 
equivalent of a city such as Düsseldorf, Leipzig, Bremen or Nuremberg as a result of the birth deficit. An annual immigration comparable to the average migration balance of Germany since 1950-2012, namely of 168,863 , could only compensate for almost one-third of the birth deficit.

In summary, Germany will experience a dramatic population decline if fertility remains at its current level. The German age structure enhances decline; the birth deficit is growing from year to year because of an accelerating dynamic. The population decline can, however, be slowed by an increasing fertility rate, just as it can be through continuously high immigration levels.

\section{$5 \quad$ The impact of ageing}

The consequences of the ageing process are serious for several policy fields. In particular, social insurance is massively affected by it (inter alia Castles 2004; Schmid et al. 2000). This section focuses on the most important effects for the social systems, economic development and the labour market, but also potential societal and cultural changes, as well as implications for competition between political parties.

\subsection{The impact of ageing on the social systems}

The anticipated doubling of the age dependency ratio from about 2010 to 2040 has immediate consequences for social insurance. The problems are greater in countries with pay-as-you-go pension systems as well as in countries with ambitious social systems which have a high degree of decommodification and in countries with a low birth rate. Hence, the problems are particularly pronounced in Germany. These problems and their potential solutions are presented in greater detail below using the pension formula. In simplified terms, the pension formula is made up of these five variables:

$$
c=A D * P R * \frac{a(P)}{a(W)} * \frac{1}{T}
$$

The contribution rate (c) corresponds to the age dependency ratio (AD) multiplied by the pension replacement rate (PR), multiplied by the ratio of pensioners ${ }^{4}$ $(a(P))$ and workers $(a(W))$, multiplied by the reciprocal value of the tax share $(T)$. An example using the pension formula: If the age dependency ratio doubles and everything else remains constant, the contribution rate automatically doubles as well such high ancillary wage costs would have a dramatic impact on the labour market. If one wishes to keep the contribution rate constant, all other things being equal, the pension replacement rate would be halved, and widespread pension poverty would

4 The percentage of pensioners among the population aged $60(65)$ and older in relation to the working population in this age group. 
be the consequence. An adjustment via the retirement age would correspond to a de facto retirement age of 71, and therefore a formal one of roughly 75 (cf. Rürup/ Schmidt 2003), which is illusory. Furthermore, the tax share alone could not compensate for this dimension.

All four remaining components of the pension formula have been adjusted in Germany as a reaction to the anticipated doubling of the age dependency ratio between 2000 and 2035. If one takes a look at the almost annual, incrementalistic reforms of the pension system, it is easy to attribute each of these savings measures to one of the components of the pension formula:

1) The first example is an increase in the contribution rate, which has already taken place 27 times since 1953 (Schmidt 2005). This is the most obvious adjustment. For younger people, state-subsidised investment in capital-funded pension insurance schemes is added to the contribution rates to the compulsory pay-as-you-go pension schemes. The internationalisation of the economy, however, sets limits on financing of pension schemes via added ancillary wage costs (Scharpf 2001).

2) A second possibility for adjustment is the pension replacement rate which has been reduced by measures such as a less generous allowance of years spent in training, indexing to the evolution of net wages, Blüm's demographic factor (1997), Schröder's similar sustainability factor (2004), a reduction in the allowance for schooling and higher education and the establishment of the full long-term care contribution for pensioners. The clause to maintain the pension replacement rate in accordance with section 154 subsection (3) of Book VI of the Social Code ( $S G B$ VI) only ensures the standard gross pension of a pensioner with 45 years' average earnings at the level of 43 percent in 2030 (currently 52 percent).

3) The third component of the pension formula, namely the pensioner coefficient, is adjusted by gradually increasing the formal retirement age from 65 to 67 years between 2011 and 2029. Also, early retirement has been made more difficult in Germany, for instance via section 77 of Book VI of the Social Code ( $S G B V I)$, according to which the pension replacement rate decreases by 0.3 percent per month of early retirement. Furthermore, an increase in the labour market participation of the working-age population reduces the burden on the social systems, which can be achieved, for example, by increasing women's labour force participation and reducing unemployment. Walter et al. (2013: 42) show scenarios in which a combination of these factors can reduce the decline in the working population up to 2030.

4) Tax revenue for instance flows into the pension system via the ecotax. Conversely, a burden is already being imposed on the national budget by the funding of civil servants' pensions, which is growing by virtue of demographic factors. Removing benefits which are alien to insurance, for example, constitutes a transfer from the tax system to the pension system.

The long-term reforms, the increase in the retirement age to 67 , and the sustainability factor, have already done a lot to adjust the German pension system to the increase in the age dependency ratio in the next few decades. German old-age pension policy thus became more revenue-orientated as opposed to an orientation towards a desired replacement rate. The social burdens for contributors and pensioners as well as the macroeconomic burdens on the State and industry up to 
2040 are extremely high. The argument that the pension problems brought about by the fertility decline could be compensated for by making progress in productivity (inter alia Hondrich 2007) is hardly tenable. Firstly, the shift in the age dependency ratio is too high, and secondly it is naive to presume that companies and workers will permit the entire productivity gains made over several decades only to flow into the pension funds.

The impact of ageing on statutory health and long-term care insurance is similar to that on old-age security in the sense that, here too, fewer contributors will be accounted for by more beneficiaries. The scale is similar when it comes to ancillary wage costs, but the impact of the enduring low fertility is less pronounced here for two reasons: Pensioners themselves contribute to fund the statutory health insurance, and the remaining life expectancy after retirement does not equate to years of illness. Health expenditure is more difficult to forecast since supply and demand for healthcare services does not only depend on demographic assumptions - medical progress in particular acts as a cost driver. Birg (2003: 185) calculates that the contribution rate of the health insurance funds will increase from 13 percent to $21-24$ percent by 2050 , and that the long-term care rate will quadruple to roughly 6 percent. However, in relation to GDP, and unlike the contribution rate, the benefits of statutory health insurance in Germany have remained constant for three decades (Rürup/Ranscht 2009: 112). The rise in long-term care costs is different: The drastic increase in the ratio of the very old leads to an increase in specific diagnoses requiring long-term care such as dementia, which will probably cause a considerable growth despite improvements in medical treatment (cf. Doblhammer) Scholz 2010). It is, however, necessary to distinguish here between professional and informal long-term care (Michee/ 2013). Even if there is a marked increase in public health expenditure, people will have to face a growing individual responsibility and a partial rationalisation of the benefits. This development could lead to serious socio-political conflicts.

Low fertility will require society to shift a growing share of productivity and prosperity into the social welfare systems in the next three decades, and the pension replacement rate and statutory health insurance benefits will nonetheless reduce in relative terms. This could not even be changed by a rapid increase of the fertility rate. The age dependency ratio will rise more slowly after 2040, which in turn will relieve pressure from the social welfare systems.

\subsection{The impact of ageing on industry and the labour market}

Increasing social security contributions put an indirect burden on industry and the labour market - in particular for welfare states which are ambitious and are financed to a considerable degree via the active labour force (Schmidt 2005). The consequences on the social welfare state that have been described above may have negative effects on the labour market, which can, however, be regulated by politics, if these negative effects are not largely transferred to ancillary wage costs. People occasionally argue that the shrinking supply of workers reduces unemployment. 
This is, however, based on a static understanding of supply and demand since such impacts can only occur in the short term (Friedman 1968).

There are controversial discussions whether the productivity of an older workforce changes. The hypothesis according to which ageing is accompanied by a decline in innovativeness cannot be verified. Research by Guilford is quoted in some cases (Sinn 2003: 67), according to which the greatest mental performance is reached at the age of 30-40. This hypothesis is, however, too undifferentiated since knowledge and experience increase as workers age (Akademiegruppe Altern 2009: 41). Furthermore, the fitness of 60-year-olds is constantly increasing. One central point can be influenced by politics: Investment in human capital can also enhance innovation among older workers by increasing further training activities.

The impact on industrial growth can be understood using the Cobb-Douglas production function which is made up of technical progress, labour input and capital input. Labour input understood as the labour force will decline in the next three decades in absolute and relative terms as a result of the enduring low fertility. This impact could be compensated for by even greater technical progress or more capital investment. According to various model calculations, Europe's economic growth rate could drop permanently: from 2.3 percent to 0.5 percent for 2025-2050 according to the OECD (1998). Intensifying capital (Lee/Mason 2007) or increased investment in education (Lutz et al. 2008) can, however, compensate for the negative effects of ageing. Striessnig and Lutz (2013) use simulation models controlled for education to show that fertility rates below the replacement rate could also be optimal. Focussing demographic consequences only on GDP growth has its limits since it is not equivalent to the rise in quality of life (Easterlin 1974).

In various sectors, ageing induces further shifts in demands besides these overall effects (Kaufmann 2005). For instance, long-term care services, tourism, oldpeople's homes and financial services will attract attention in the future. As another result of ageing, inheritances increase, thus opening up a large source of income for the State and increasing per capita assets.

\subsection{The impact of ageing for society and culture}

Due to the increase in life expectancy and the compression of morbidity into a small number of years, ageing is a phenomenon that is generally advantageous for many people in the sense of "years gained" (Imhof 1981). The low fertility, however, additionally entails a shift in the cohort sizes between young and old, its impact on society is ambivalent and speculative. Risk aversion could be higher in ageing societies (Kaufmann 2005), whilst on the other hand this has a highly stabilising impact in comparison to extremely young societies (Huntington 1996). The hypothesis of a quantitative reduction in family relationships and family networks (inter alia Schirrmacher 2004) is questionable in light of demographic projections (Dude/ 2014).

The terms "age", "overageing" and "ageing society" have largely negative associations, and in some cases are weighed down with clichés (Akademiegruppe Altern 2009). Schirrmacher (2004) outlines future scenarios of a "war of the generations" and "racist age stereotypes". Kruse (2013), by contrast, points to potentials 
such as differentiated knowledge, reflected experience, resilience, generativity and gerotranscendence. Höhn et al. (2006) show that people in OECD countries are not hostile to the elderly, and that the experience of older people is appreciated. Furthermore, it should be taken into account that the 70 -year-olds of the future will be much healthier, more mobile and more independent than 70 -year-olds in the past. In this regard, the third stage of life of retirees and those drawing a pension provides enormous opportunities, both individually and in terms of civil society, for instance through (community) volunteering of this age group. Moreover, there are diverse relationships and transfers when it comes to intergenerational relationships where elderly people have great potential to take part and give support. Relationship quality is of great importance in this case (see Ette et al. 2010 for details). The societal impact of ageing is not only highly speculative, but also depends on how policy makers and society deal with it. Here, the Research Group Ageing (Akademiegruppe Altern 2009) is calling for a re-think at the individual level of traditional life course concepts, for continuous investment in qualifications at the level of companies, and for overcoming a negative perception of age at the societal level.

\subsection{The impact of ageing on party competition}

As was shown above, the median age of voters will increase by 2040 to such an extent that pensioners and persons about to retire will form a majority in the electoral system. This means that people who are no longer working will make decisions that primarily affect the working age population. The question is how these interests will impact the party political system and political decision-making - whether they may even lead to a "gerontocracy".

Voters' long-term loyalties to parties and to social environments, and the adaptation of the parties to perpetuate the existing system, suggest that pensioners' interests will be asserted within the party system. It is also difficult to imagine age constituting a line of conflict since both sides mostly occur in the life course (Goerres 2007). However, particularly the catch-all parties like SPD (Social Democratic Party of Germany) and CDU/CSU (Christian Democratic Union of Germany) could mutate to become parties which especially represent the interests of pensioners, especially because pensioners are their most loyal electorate. One such example is the Coalition Agreement of the third Grand Coalition, which provides for a pension for women with children born before 1992 and a pension at 63 for people who have contributed to the pension system for at least 45 years (CDU, CSU, SPD 2013). When catch-all parties are too ambitious representing the interests of pensioners, they might enable smaller parties to establish as advocates for the under 50-year-olds. Differences between old and young can already be seen when analysing attitudes towards the pension policy and voting behaviour (Bergmann et al. 2012).

A variety of future scenarios is conceivable: The line of conflict between old and young, and between beneficiaries of and contributors to the social welfare state, could be reflected in the party system as well as in the union structure, which might cause the struggle for resources to become more extreme with regard to party competition and polarising rhetoric in the media. The preference in favour of social 
expenditure such as pensions or education depends on age to a considerable degree (Busemeyer et al. 2009). It would, however, also be possible that this conflict is taken up and channelled by the established parties and interest groups which allow older lines of conflict to remain dominant. Since older people show a considerable interest in the welfare of the younger generations, especially if they themselves have children and grandchildren, compromise between the interests of different generations is also conceivable (cf. Bergmann et al. 2012). A conflict line between childless people and families would appear more likely in this regard since the former do not have any such relationship establishing ties between the generations. A sustainable family policy promoting births and being orientated towards the well-being of children would also encourage solidarity between the generations, and such a policy would directly benefit the young generation, the older generation would indirectly profit via the weakening in pressure from demographic problems.

\section{The impact of the population decline}

\subsection{The impact of the population decline on international relations and the EU}

There are several historical examples of the demographic impact on a country's strength in terms of foreign and defence policy. A decline in Europe's political power was already predicted in 1945 by Davis (1945: 603). The influence of the shifts in the demographic weights between France, Germany and Russia on the military strength in the 19th and early 20th Centuries was frequently discussed - also in the context of the outbreak of the First World War (Morgenthau 1948: 123). The economic and power political aspects of the population size also played a major role in the mercantile era or in Ancient times, with regard to the Fall of Rome.

There is no doubt that the population decline will lead to a relative loss of foreign policy significance in the particularly adversely affected states of Europe and East Asia. Statements such as the "demographic demise of Germany and Europe" suggested in Birg (2003: 14) are, however, untenable on the basis of demographic analyses. The "shift in international weights" (Wöh/cke et al. 2004: 11) has implications for international relations which are particularly interesting with regard to the political sciences. From a (neo)realistic perspective (Morgenthau 1948), a nexus of a population decline and a loss of power can be derived from the resulting weakening of military power and, from the point of view of interdependency theory (Keohane/ Nye 1977), from a decline in the influence exercised in international organisations such as the UN and NATO, but also the EU. The population size has a direct impact where a legitimation is derived from the democratic principle - such as the qualified majority in decisions of the European Council. Moreover, when there is a population decline, the economic power and hence also the military potential decrease - in particular in relation to those states whose population and economic power still increase. Whether the EU can become established as a global power alongside the US and China will not solely depend on demographic developments. The EU-28 would 
still have well over 300 million inhabitants in 2100 were its TFR to remain constant. Rather, the development of the political criteria is decisive, that is the degree to which foreign and defence policy integration within the EU leads to the "ability to take political action, political consensus and experience of order" (Weidenfeld 1995; translated by CPoS).

Demographic developments will reduce Germany's present dominance within the $\mathrm{EU}$ in the long term. Germany is not only the strongest member in economic terms, but also has the largest population, with almost 20 million inhabitants more than France and the United Kingdom. The margin will have shrunk to less than 10 million in 2030, all three states will be at the same level in the 2040s, and both may overtake Germany 30 years from now. When it comes to the impact on Germany's status within the EU, there is a need to distinguish between the democratic principle and economic power: The balance of power in the EU's Council of Ministers will shift in the next few decades since the majority decisions require a qualified majority meaning 55 percent of EU countries and at the same time these have to represent 65 percent of the EU's population. This leads to new structural majorities and blocking minorities (Münch/Wilkoszewski 2006), and Germany's influence will decline in line with the above projections. The same applies to Germany's representation in the European Parliament (EP). Secondly, the enduring low fertility reduces the country's overall economic power more severely than what is calculated on a per capita basis. Even given all the uncertainty with regard to the long-term economic development - in demographic terms -, a considerable decline in Germany's economic dominance seems plausible. Today's internal EU migration to Germany has massive foreign policy implications against this background.

\subsection{The impact of the population decline for the economy}

Several economic theories are based on the nexus between population size and the economy. According to Adam Smith (1776), population growth increases the potential in terms of the division of labour and economies of scale. The opposite conclusion of the population decline is however of subordinate significance when it comes to large internal markets such as the EU and globalised commodity markets. Keynes regards the slight population decline as having contributed towards the weak demand in the Great Depression at that time. Several neoclassical approaches externalise the population development (inter alia Friedman 1968). Solow's theory of economic growth (1956), by contrast, analyses the interaction between population growth, income and investment. According to his theory, the per capita stock of capital falls as population growth increases, and conversely population decline can hence lead to an increase in per capita investment and per capita gross domestic product (per capita GDP). From a neoclassical point of view, a shortage of labour force can be substituted by an increase in capital investment. Accordingly, total GDP can increase even if there is a population decline if technical progress and investment overcompensate for this.

In order to bring about technical progress, however, it is especially good training of as many workers as possible that is significant, and not only capital investment. 
This is also discussed by human capital theory (Schultz 1971). Since human capital is made up of the product of workforce and its average skills, a population decline can be theoretically compensated for by investing in education (Lutz et al. 2008). To this end, investment in education in countries with a TFR of around 1.4 would, however, have to be much greater than in countries with higher fertility. Since this has not been the case in Germany since 1975 despite a net reproduction rate of 0.59 to 0.69 , Kaufmann (2005) calculates an investment deficit in human capital of 2.5 trillion euros.

It can, however, be questioned to solely determine the economic impact on growth by a country's GDP: Per capita GDP is much more significant in terms of prosperity, both now and in the future, than total GDP, given that a population decline may cause GDP to fall, whilst per capita GDP rises.

If one looks at the assets of the national economy instead of growth, a more positive result is reached since per capita assets increase if the denominator becomes smaller and all other things being equal. However, public debt also increases in the case of a population decline when looking at per capita rates. The two together suggest the conclusion that greater taxation on assets would then make sense. Another major aspect relates to the concentration of assets and to distributive justice, which in future might have to be brought about through greater taxation on inherited assets. A growing group of individuals will not be able to leave assets to their own children since the number of childless women and men has risen to more than 20 percent (based on the 1960s cohorts, cf. Statistisches Bundesamt 2013a). The volume of inheritance tax could be greater in relative terms in this group if the taxation of inheritance to direct offspring is favoured by means of providing for exemptions. If one looks at prosperity from the perspective of Sen (1995), who stresses the opportunities for participation, a positive impact is even possible: Given the fact that cohorts are smaller, and because of the need for well-trained workers, there will be increasing economic incentives to train those sections of society with lower educational levels in order to "enable" them to participate.

The population decline will lead to a huge structural transformation which will be especially dramatic in rural regions. Because of internal migration, particularly of the young population to urban regions where there are jobs, the population decline in some urban regions will be compensated for and intensified still further in deindustrialised and rural regions. This impact becomes already visible in Eastern Germany today. However, some towns and cities will also shrink. These regional disparities entail major challenges for public welfare, particularly services offered and public infrastructure such as schools, kindergartens, hospitals, long-term care facilities or the fire service (cf. BMI 2012; Steinführer et al. 2014). The impact on rental and real estate markets in the shrinking rural regions is considerable, being positive for tenants and negative for real estate owners.

\subsection{The impact of the population decline on the environment}

The impact of the population decline in terms of energy and the environment, by contrast, is positive since the consumption of resources and environmental pollu- 
tion decreases as the population becomes smaller, all other things being equal. At the national level, a population decline could be used for re-naturalisation in some regions. The global perspective is, however, much more significant here since resource consumption in industrialised countries such as Germany is disproportionately high (see also: Meadows et al. 1972). Since Meadows' publication, per capita resource consumption in the industrialised countries has increased with regard to most types of resources. The per capita ecological footprint increased by 30 percent in Europe between 1961 and 2007 and by 42 percent in Germany (Ewing et al. 2010: 63). A standard for sustainability is that the environmental resources used can be regenerated in the long term. This is not the case in a global perspective which is expressed in climate change and the loss of biodiversity as well as in increasing resource shortages in terms of energy, water or fish stocks. In this respect, a population decline can be seen as an opportunity to reduce resource consumption and climate change.

The potential for savings in Germany should however be placed into a global perspective: Firstly, the population of Germany only accounts for 1.1 percent of the world's population, and this share is declining (UN 2012). Secondly, resource consumption is massively increasing in the developing and threshold countries, in which the largest share of the world's population lives. The following figures on resource consumption, measured in global hectares per person (gha) in 2007 make the ratios clear: The ecological footprint of production in Germany is $4.72 \mathrm{gha}$, and that of consumption is 5.08 gha, whilst biocapacity is 1.92 . This per capita shortfall that has been calculated is multiplied by the population size. According to that, 2.65 times as many resources are consumed in Germany in comparison to biocapacity. Globally, "only" 1.52 times the resources are consumed (Ewing et al. 2010: 31). Accordingly, the German deficit, at 165 percent, is more than three times as large as the global one at 52 percent. If the population size declines, per capita biocapacity increases according to this model.

In addition to this impact, the symbolic effect should not be underestimated if, in an industrialised country, resource consumption and the size of the population decrease. Moreover, the findings can also be transferred to other countries, and a population decline in several industrialised countries might cause a considerable relief to the environment. Apart from this demographic argument, there are other political and technological possibilities to reduce environmental burdens.

\subsection{The impact of the population decline on society and culture}

It is difficult to estimate the cultural impact. Most social institutions such as the Churches, trade unions, political parties and associations will lose members. The term "depopulation", or even the analogy with the Thirty Years' War (Schmid et al. 2000: 184), are not appropriate as such, given a population decline of 14 to 21 percent by 2060 according to the medium projections. However, there are regions in which emigration coincides with low fertility, which might constitute a dramatic depopulation for those who remain. This is particularly the case in some regions of Eastern Germany, albeit this is not only caused by East-West migration, but also by 
migration between Eastern German regions (Sander 2014). What societal impact this will have also depends on the compensating effect of regional politics. In addition to these weak regions, there will be prosperous towns, cities and regions whose population will not decline in the following decades.

It is the population which is the medium of a country's culture and language. If it shrinks, the number of people who understand and speak the language, and who live and pass on the cultural traditions, also declines. The community characterised as sharing a common communication, experience as well as a common memory establishing the collective identity (Kielmannsegg 1995) become smaller as a result of the population decline. The degree to which a decline in cultural significance in an international comparison or a smaller medium for cultural and historical experience is regarded as being negative is evaluated very differently. The attempt, despite the constant level of immigration, to permanently exclude people with a migration background from these "communication communities" over generations (be it via population projections, cf. Birg 2003) is a falsehood - not only because it presumes a lack of willingness to become integrated and of the effect of integration policy for the future, but also in view of mixed family formation and the impact of nationality law.

\section{Conclusion, synthesis and discussion}

The case study on Germany shows that the impact of the enduring low fertility depends to a considerable degree on political decisions, but also on the future migration rate. The extreme assessments of some authors are not appropriate. The change in German fertility is neither a "blessing", nor will it lead to the "demise of Germany". Enduring low fertility leads to two demographic processes, namely ageing and a population decline, which both have a massive impact on the future societal, political and economic development. The intensity, time and evaluation of the impact differ depending on the policy area. In an overall evaluation, the impact is largely negative, partly ambivalent and manifests itself in the long term with a considerable intensity - according to this paper. This contradicts the increasingly occurring evaluations which suggest a neutral overall balance of the impact of the enduring low fertility with its challenges and opportunities. On the other hand, the consequences for party competition, culture, the labour market and the economy are not necessarily negative since they depend on political decisions and evaluation perspectives.

This overall evaluation needs to be accompanied by general distinctions regarding demographic projections as well as political, economic and cultural consequences:

(1) Some demographic effects are certain, whilst others are based on scenarios where we do not know whether they will come about. Ageing is almost certain, and in particular the fact that the age dependency ratio will more than double from 2000 to 2040 . The 20-65 age dependency ratio, which was 33.7 in 2008 , will be between 57 and 66 in 2040 . There is also certainty that the 
median voter age will rise from today's 50.1 to roughly 55 years by 2030 , with a further increase in the subsequent years. The situation is slightly different when it comes to the population decline: It is an open question even today whether and to what extend we will actually experience it. The population would be around 82-83 million by 2060 if the TFR does soon increase to 2.1 and under the condition of a moderate migration balance of 100,000 . This scenario is not the most probable one, but it is also not entirely unrealistic. In more realistic scenarios with a TFR between 1.2 and 1.6 , the population will be between 74 and 78 million by 2040 and between 61 and 77 million by 2060 . If, however, the TFR were to remain at the same low level for the next 86 years and the migration balance does not increase, the German population would shrink considerably to 43.4 million. Such long-term projections are, however, highly speculative.

(2) Some political developments can be shaped in such a way that they cannot generally be categorised in the dichotomy of "positive-negative"; others, in turn, are negative irrespective of possible structural adjustments. The most negative development relates to the impact on the social systems. Even if the halving of the pensions (which, all other things being equal, would correspond to doubling the age dependency ratio) can be avoided by combining a higher de facto and legal retirement age, tax subsidies, an increase in the contribution rates and higher female labour force participation, and horror scenarios are thus avoidable: The enduring low fertility considerably reduces future prosperity. Without ageing, the increase in the de facto retirement age and in female labour force participation would lead to higher pensions and lower ancillary wage costs. Pensions will be lower for several decades from 2030 onwards and the benefits provided by the health insurance funds will be more restricted, leading to rising pension poverty and exclusion from some healthcare services. Moreover, a considerable share of the increase in the productivity of the working generations will be used to fund social security systems.

The impact on party competition results from the increase in the median age of voters: The electoral influence exerted by pensioners increases rapidly. The question remains to what degree this leads to reforms being blocked or changes in the political party system. Such scenarios become likely when thinking of pensioners' shared monetary interests in questions related to distribution, but, on the other hand, are being objected when thinking of the ability of political parties to adapt and of the intergenerational solidarity of the electorate. Within the EU, the relative weight of Germany might decrease as a result of the enduring low fertility. In the 2040s, France and the United Kingdom will have a similar population size to that of Germany. This will have a direct impact via the qualified majority in the Council and the number of EP members, as well as indirectly via negotiation positions and industrial power.

(3) The economic impact of the low fertility in Germany differs. The impact on potential growth and GDP tends to be negative because of the higher age dependency ratio (ageing) and the decline in human capital (population decline). However, the decline of the working population can be compensated for by higher level of labour market participation, a larger capital stock and especially higher education. Negative overall effects on the per capita GDP are not plausible, however. The more severe the population decline, the more the per capita public debt will increase, but this also applies to per capita assets. The sectoral shifts in demand will be considerable. On the regional level, the impact of the population decline will substantially differ due to unequal internal 
migration. There will be deserted regions with falling real estate prices facing regional policy challenges, just as there will be prosperous towns and cities.

(4) The cultural impact of ageing will vary widely. Negative age stereotypes are rather unrealistic since pensioners will be healthier and fitter than was the case in earlier generations. (Community) Volunteering and the public perception of the pensioners' generation will increase. The extent of an impact on cultural in the case of enduring low fertility - a scenario which is possible but not certain - is difficult to assess in normative terms. The language media and common memory would reduce in size. This, however, will have virtually no impact on everyday cultural life, but the international profile might be weakened. Since, at the same time, the share of people with a migration background will increase, culture will also become more diverse. Evaluations of this development are highly subjective. Integration policy and language skills will certainly take on an increasingly important role. A common communication, experience as well as a common memory can relate both to past centuries, as well as to shorter periods of time which are shared by people with and without a migration background.

Table 1 summarises for each analysed policy area the demographic probability of certain possible impacts, their time horizon, the policy options and an evaluation of the impact.

The question whether ageing or rather a population decline is associated with worse consequence of the enduring low fertility for people can be answered now: it is ageing. First, because it is certain that the age dependency ratio will double by 2040 , whilst a population decline by more than 20 percent is by no means certain. Secondly, ageing has a massive impact on the social systems, and hence on the prosperity of almost all Germans. The most serious consequence of a population decline, on the other hand, namely a possible "cultural demise of Germany", will be virtually intangible in everyday life unless it results in a lack of integration of migrants. This, however, would not be a consequence of low fertility. From the perspective of the state, however, the population decline indeed has a negative impact since it contributes to a decline in international influence and power.

One central finding is that an analytical distinction brings about a major advantage when analysing the impacts of ageing and the impacts of the population decline since the two differ substantially with regard to the time horizon, the dynamic and the influence of migration and increasing life expectancy. This partly explains the heterogeneous interpretations since the literature does frequently not distinguish precisely between these demographic processes.

Those authors who deny the negative impact of the Second Demographic Transition (inter alia Müller 2004; Hondrich 2007), do not similarly perceive the highly negative consequences for the social security systems. Given the doubling of the age dependency ratio, it is frequently argued that future growth in productivity as well as migration might compensate for ageing but without giving detailed references. Both are, however, seriously overestimated in relation to the dynamic of ageing. Furthermore, developments of the two demographic transitions (FDT and SDT) are mixed, and misleading analogies are drawn. On the other hand, scenarios put forward by some demographers, who stress the negative consequences of the enduring low fertility (inter alia Schmid et al. 2000; Birg 2003), are clearly exagger- 
ated. This is contributed to by the specific selection of (negative) assumptions, and by the failure to categorise the uncertainty attached to long-term model calculations in case of the population decline.

If, however, evaluations do not only relate to low fertility, but to the demographic change as a whole, a normative neutral evaluation is not implausible (inter alia Merke/ 2013). Since it entails a positive phenomenon, namely the increase in life expectancy (Akademiegruppe Altern 2009; Kruse 2013), and a negative one in the enduring low fertility. These two phenomena are, however, not interdependent. Whilst increasing life expectancy affects all industrialised countries, only some of the countries, such as Germany, are characterised by low fertility.

How can findings derived from the case study on Germany be transferred to other countries? Low fertility rates do not have such consequences if they are only low for a few years. In Germany, by contrast, the enduring low fertility has taken on a dynamic force since it already stretches across two generations now. Some Southern and Eastern European states, as well as Japan and South Korea, currently face a similar development. If the low-fertility syndrome lasts for a similar period in these countries as it does in Germany, the shrinking process in Southern and Eastern Europe will be even more pronounced since Germany has benefited from considerable net immigration in recent decades and some of these countries are affected by waves of emigration. Since Germany is an immigration destination country to which many people have moved from Southern and Eastern Europe, because of the wave of ethnic German resettlers from the (former) Soviet Union after the fall of the Iron Curtain, as well as due to the financial crisis, the shrinking process set in motion by an enduring low fertility has been compensated for. This is not the case for Japan; here the age dependency ratio will rise greater than in Germany since life expectancy is several years higher there. Countries such as France with a more pronounced baby boom also have problems with the pensions system despite a TFR around the replacement level, since the age dependency ratio also rises rapidly when the baby boomer generation reaches retirement age.

In the first two decades after the start of low fertility in 1975, Germany did not react to the impact on the social systems, or only did so by enacting minor reform measures. The more extensive pension reform, which increased the retirement age by two years, was adopted in 2007, and thus in the 33rd year in which the TFR was lower than 1.5. An official interdepartmental Demography Strategy was presented in 2012, in Germany's 38th year as a low-fertility country. The more visible the age effect and the population decline, the more intensive becomes the political and media debate on demography. As has been shown, the German debate on demography features considerable exaggerations and extreme positions. This situation may not be transferable to other countries since the experience with pronatalistic abuse in Nazi Germany has cast a long shadow over the debate. On the other hand, the discussion of the demographic impact is made more complicated when researcher describe specific developments which cannot yet be seen by the citizens. The impact for the economy, the labour market, the environment and party competition can also largely be transferred to other countries if the phenomenon of low fertility lasts for a similarly long period there. The impact on the balance of power within 
the EU is particularly serious from the perspective of Germany since Germany has a leading position regarding the size of its economy and of its population, and might lose its position should there be a considerable population decline. On the contrary, when it comes to other countries such as Estonia the cultural impact is huge since the language media and the common memory there are relatively small.

Since the occurrence of enduring low fertility is a phenomenon which has taken on a new dimension, many effects are still uncertain and are subject to future research. Immigration may decelerate the population decline, possibly at the expense of additional problems, but this has no effect on ageing. The analysis of the impact shows that countries such as Germany have a fundamental interest in increasing future birth rates. The potential long-term impact of a mixture of family policies on the TFR (Bujard 2011; Luci-Greulich/Thévenon 2013) makes family policy a key policy area in the future. The impact on social insurance within the next two decades can, however, no longer be averted by demographic means. If, however, the fertility rate rises to replacement level, the age dependency ratio could be 26 percent lower by 2060 compared to a scenario with a constant low TFR. This would imply long-term latitude to increase pensions for the generations born after 1970. In order to avert the projected population decline, an increase in the TFR would be the central adjustment. Even if it does not increase within the next one, two or three decades, the negative scenarios of an exponential population decline could be averted.

\section{Acknowledgement}

The author wishes to thank Christian Fiedler, Frank Micheel, Harun Sulak and Stefan Wurster, as well as two anonymous reviewers for their valuable advice.

\section{References}

Akademiegruppe Altern in Deutschland 2009: Gewonnene Jahre. Stuttgart: Wissenschaftliche Verlagsgesellschaft.

Barlösius, Eva; Schiek, Daniela (Eds.) 2007: Demographisierung des Gesellschaftlichen. Analysen und Debatten zur demographischen Zukunft Deutschlands. Wiesbaden: VS Verlag.

Basten, Stuart; Sobotka, Tomáš; Zeman, Krystof 2013: Future Fertility in Low Fertility Countries. Vienna Institute of Demography Working Papers 5/2013.

Bergmann, Michael; Konzelmann, Laura; Rattinger, Hans 2012: Deutschland auf dem Weg in die „Rentner Demokratie“? In: Politische Vierteljahresschrift 53: 371-393.

Birg, Herwig 2003: Die demographische Zeitenwende. 3. Auflage. München: Beck.

Blue, Laura; Espenshade, Thomas J. 2011: Population Momentum Across the Demographic Transition. In: Population and Development Review 37,4: 721-747 [doi: 10.1111/j.1728-4457.2011.00454.x].

Bongaarts, John 2001: Fertility and Reproductive Preferences in Post-Transitional Societies. In: Population and Development Review 27: 260-281.

Bujard, Martin 2011: Geburtenrückgang und Familienpolitik. Baden-Baden: Nomos. 
Bujard, Martin et al. 2012: (Keine) Lust auf Kinder? - Geburtenentwicklung in Deutschland [http://www.bib-demografie.de/geburtenentwicklung2012, 05.05.2015].

BMI (Bundesministerium des Innern) 2012: Demografiebericht. Berlin: BMI.

BMI (Bundesministerium des Innern) 2013: Jedes Alter zählt. Demografiestrategie der Bundesregierung. Berlin: BMI.

Busemeyer, Marius; Goerres, Achim; Weschle, Simon 2009: Attitudes towards redistributive spending in an era of demographic ageing: the rival pressures from age and income in 14 OECD countries. In: Journal of European Social Policy 19,3: 195-212 [doi: 10.1177/0958928709104736].

Castles, Francis G. 2004: The Future of the Welfare State. Crisis Myths and Crisis Realities. Oxford: University Press.

CDU, CSU, SPD 2013: Deutschlands Zukunft gestalten. Koalitionsvertrag zwischen CDU, CSU und SPD [http://www.cdu.de/artikel/der-koalitionsvertrag-von-cdu-csu-und-spd, 16.12.2013].

Davis, Kingsley 1945: The World Demographic Transition. In: The Annals of The American Academy of Political and Social Science 237: 1-11 [doi: 10.1177/000271624523700102].

Doblhammer, Gabriele; Scholz, Rembrandt (Eds.) 2010: Ageing, Care Need and Quality of Life. Wiesbaden: VS Verlag.

Dudel, Christian 2014: Vorausberechnung von Verwandtschaft. Opladen: Barbara Budrich.

Easterlin, Richard A. 1974: Does economic growth improve the human lot? In: David, Paul A.; Reder, Melvin W. (Eds.): Nations and households in economic growth: Essays in honor of Moses Abramovitz. New York: Academic Press: 89-125.

Ette, Andreas; Ruckdeschel, Kerstin; Unger, Rainer (Eds.) 2010: Potenziale intergenerationaler Beziehungen. Chancen und Herausforderungen für die Gestaltung des demografischen Wandels. Beiträge zur Bevölkerungswissenschaft, Band 40. Würzburg: Ergon.

Ewing, Brad et al. 2010: The Ecological Footprint Atlas 2010. Oakland: Global Footprint Network.

Friedman, Milton 1968: The Role of Monetary Policy. In: American Economic Review 58: 1-17.

Goerres, Achim 2007: Can We Reform the Welfare State in Times of "Grey" Majorities? In: MPIfG Working Paper 07/5.

Goldstein, Joshua; Rößger, Felix; Jaschinski, Ina; Prskawetz, Alexia 2011: Fertility Forecasting in the German-speaking World: Recent Experience and Opportunities for Improvement. In: Comparative Population Studies 36,2-3: 661-692 [doi: 10.4232/10. CPoS-2011-09en].

Höhn, Charlotte; Ette, Andreas; Ruckdeschel, Kerstin 2006: Kinderwünsche in Deutschland. Stuttgart: Robert Bosch Stiftung.

Hondrich, Karl 2007: Weniger sind mehr. Frankfurt: Campus.

Hüther, Michael; Naegele, Gerhard 2013: Demografiepolitik. Wiesbaden: Springer VS.

Huntington, Samue/ 1996: Kampf der Kulturen. München: Siedler.

Imhof, Arthur 1981: Die gewonnenen Jahre. München: Beck.

Kaufmann, Franz-Xaver 2005: Schrumpfende Gesellschaft. Frankfurt: Suhrkamp.

Keohane, Robert O.; Nye, Joseph S. 1977: Power and Interdependence. World Politics in Transition. Boston/Toronto: Little, Brown and Company. 
Kielmansegg, Peter Graf 1995: Läßt sich die Europäische Union demokratisch verfassen? In: Weidenfeld, Werner (Ed.): Reform der Europäischen Union. Gütersloh: Bertelsmann.

Kolk, Martin; Cownden, Daniel; Enquist, Magnus 2014: Correlations in fertility across generations - can low fertility persist? Proceedings of the Royal Society B, 281: 20132561 [doi: 10.1098/rspb.2013.2561].

Kruse, Andreas 2013: Alternde Gesellschaft - eine Bedrohung? Berlin: Lambertus.

Kühntopf, Stephan; Stedtfeld, Susanne 2012: Wenige junge Frauen im ländlichen Raum. BiB Working Paper 3/2012. Wiesbaden: Bundesinstitut für Bevölkerungsforschung.

Lee, Ronald; Mason, Andrew 2007: Population Aging, Wealth, and Economic Growth: Demographic Dividends and Public Policy. WESS Background Paper.

Luci-Greulich, Angela; Thévenon, Olivier 2013: The Impact of Family Policies on Fertility Trends in Developed Countries. In: European Journal of Population 29,4: 387-416 [doi: 10.1007/s10680-013-9295-4].

Lutz, Wolfgang; Cuaresma, Jesus Crespo; Sanderson, Warren 2008: The demography of educational attainment and economic growth. In: Science 319,5866: 1047-1048 [doi: 10.1126/science.1151753].

Mayer, Tilman 2012: Demografiepolitik. BDF Working Paper 2-2012. Berlin: BDF.

Meadows, Donella H. et al. 1972: The Limits to Growth. New York: Universe Books.

Merkel, Angela 2012: Rede anlässlich des "Demografiegipfels“. 4.10.2012 [http://www. bundesregierung.de/Content/DE/Rede/2012/10/2012-10-04-bkin-demografiegipfel. html, 6.11.2013].

Merkel, Angela 2013: Rede beim zweiten Demografiegipfel. 14.5.2013 [http://www. bundesregierung.de/Content/DE/Rede/2013/05/2013-05-14-merkel-demografie.html, 6.11.2013].

Micheel, Frank 2013: Löst ein höheres Geburtenniveau die Problematik des abnehmenden Pflegepotenzials? In: Bundesgesundheitsblatt 56: 1104-1111 [doi: 10.1007/s00103013-1750-1].

Morgenthau, Hans 1963 [e. A. 1948]: Politics Among Nations. 3. Ed. New York: Knopf.

Müller, Albrecht 2004: Die Reformlüge. 40 Denkfehler, Mythen und Legenden, mit denen Politik und Wirtschaft Deutschland ruinieren. München: Droemer.

Münch, Ursula; Wilkoszewski, Harald 2006: Demografischer Wandel und Machtverteilung in Europa. In: Jahrbuch des Föderalismus. Hrsg. EZFF. Baden-Baden: Nomos: 533-551.

OECD 1998: The Macroeconomic Implications of Ageing in a Global Context. Economic Department Working Papers No. 193. Paris: OECD.

OECD 2014: OECD Family Database [www.oecd.org/social/family/database, 24.1.2014].

Rürup, Bert; Schmidt, Renate 2003: Nachhaltige Familienpolitik im Interesse einer aktiven Bevölkerungspolitik. Berlin: BMFSFJ.

Rürup, Bert; Ranscht, Anja 2009: Familienpolitik und soziale Sicherung. In: Biedenkopf, Kurt; Bertram, Hans; Niejahr, Elisabeth (Eds.): Starke Familie. Stuttgart: Robert Bosch Stiftung: 106-119.

Sánchez Gassen, Nora E. 2015: Germany's future electors. Wiesbaden: Springer VS.

Sander, Nikola 2014: Internal Migration in Germany, 1995-2010: New Insights into EastWest Migration and Re-urbanisation. In: Comparative Population Studies 39,2: 217246 [doi: 10.12765/CPoS-2014-04en]. 
Scharpf, Fritz 2001: The Viability of Advanced Welfare States in the International Economy. In: Leibfried, Stephan (Ed.): Welfare State Futures. Cambridge: University Press: 123-150.

Scherbov, Sergei; Mamolo, Marija; Lutz, Wolfgang 2008: Probabilistic Population Projections for the 27 EU Member States. European Demographic Research Papers 2. Vienna: VID.

Schmid, Josef; Heigl, Andreas; Mai, Ralf 2000: Sozialprognose. Die Belastung der nachwachsenden Generation. München: Olzog.

Schmidt, Manfred G. 2005: Sozialpolitik in Deutschland. 3. Auflage, Opladen: Leske + Budrich.

Schirrmacher, Frank 2004: Das Methusalem-Komplott, München: Blessing.

Schultz, Theodore W. 1971: Investment in Human Capital. New York: The Free Press.

Sen, Amartya K. 1993: Capability and Well-Being. In: Sen, Amartya K.; Nussbaum, Martha (Eds.): The Quality of Life. Oxford: University Press: 30-53.

Sinn, Hans-Werner 2003: Das demografische Defizit. In: Leipert, Christian (Ed.): Demographie und Wohlstand. Opladen: Leske + Budrich: 57-88.

Sinn, Hans-Werner 2013: Das demographische Defizit - die Fakten, die Folgen, die Ursachen und die Politikimplikationen. In: ifo Schnelldienst 66,21: 1-23.

Smith, Adam 1776: An Inquiry into the Nature and Causes of the Wealth of Nations. Dublin: Printed for Messrs.

Sobotka, Tomáš 2008: Overview Chapter 7: The rising importance of migrants for childbearing in Europe. In: Demographic Research 19, 9: 225-248 [doi: 10.4054/ DemRes.2008.19.9].

Solow, Robert M. 1956: A Contribution to the Theory of Economic Growth. In: The Quarterly Journal of Economics 70: 65-94.

Statistisches Bundesamt 2009a: Bevölkerung Deutschlands bis 2060. 12. koordinierte Bevölkerungsvorausberechnung. Wiesbaden: Destatis.

Statistisches Bundesamt 2009b: Bevölkerung Deutschlands bis 2060. Ergebnisse der 12. koordinierten Bevölkerungsvorausberechnung. Excel Datei. Wiesbaden: Destatis.

Statistisches Bundesamt 2013a: Geburtentrends und Familiensituation in Deutschland. Wiesbaden: Destatis.

Statistisches Bundesamt 2013b: Bevölkerung. Wanderungen Deutschland [https:// www.destatis.de/DE/ZahlenFakten/Indikatoren/LangeReihen/Bevoelkerung/Irbev07. html, 07.01.2014].

Steinführer, Annett; Küpper, Patrick; Tautz, Alexandra 2014: Adapt and Cope: Strategies for Safeguarding the Quality of Life in a Shrinking Ageing Region. In: Comparative Population Studies 39,2: 345-370 [doi: 10.12765/CPoS-2014-07en].

Stock, Günter et al. (Eds.) 2012: Zukunft mit Kindern. Frankfurt: Campus.

Striessnig, Erich; Lutz, Wolfgang 2013: Can below-replacement fertility be desirable? In: Empirica 40,3: 409-425 [doi: 10.1007/s10663-013-9213-3].

Swiaczny, Frank 2014: How Much Influence Can We Have on Demographic Trends? In: Journal of Social Demogracy, International Quarterly Edition 2014, 1: 27-30.

UN (United Nations) 2000: Replacement Migration: Is it a Solution to Declining and Ageing Populations? New York: UN.

UN (United Nations) 2012: World Population Prospects: The 2012 Revision. New York: UN. 
van de Kaa, Dirk 1987: Europe's Second Demographic Transition. In: Population Bulletin 42. Washington DC: Population Reference Bureau.

Walter, Norbert et al. 2013: Die Zukunft der Arbeitswelt. Stuttgart: Robert Bosch Stiftung.

Weidenfeld, Werner 1995: Europa - Weltmacht im Werden. In: Internationale Politik 5-1995: 17-22.

Wöhlcke, Manfred; Höhn, Charlotte; Schmid, Susanne 2004: Demografische Entwicklungen in und um Europa. Politische Konsequenzen. Baden-Baden: Nomos.

World Bank 2014: World Development Indicators [http://data.worldbank.org/data-catalog/world-development-indicators, 1.8.2014].

Translated from the original text by the Federal Institute for Population Research, for information only. The reviewed and author's authorised original article in German is available under the title "Folgen der dauerhaft niedrigen Fertilität in Deutschland. Demografische Projektionen und Konsequenzen für unterschiedliche Politikfelder", DOI 10.12765/CPOS-2015-06de or URN urn:nbn:de:bibcpos-2015-06de8, at http://www.comparativepopulationstudies.de.

Date of submission: 01.08.2014

Date of acceptance: 24.02 .2015

Dr. Martin Bujard ( $₫)$. Federal Institute for Population Research. Wiesbaden, Germany. E-Mail: Martin.Bujard@bib.bund.de

URL: http://www.bib-demografie.de/bujard_cv 


\section{Comparative Population Studies}

WWW.comparativepopulationstudies.de

ISSN: 1869-8980 (Print) - 1869-8999 (Internet)

Published by / Herausgegeben von

Prof. Dr. Norbert F. Schneider

Federal Institute for Population Research

D-65180 Wiesbaden / Germany

\section{Managing Editor /}

Verantwortlicher Redakteur

Frank Swiaczny

\section{Assistant Managing Editor /}

\section{Stellvertretende Redakteurin}

Katrin Schiefer

\section{Copy Editor (German) /}

Lektorat (deutsch)

Dr. Evelyn Grünheid

\section{Layout / Satz}

Beatriz Feiler-Fuchs

E-mail:cpos@bib.bund.de

\section{Scientific Advisory Board /}

Wissenschaftlicher Beirat

Paul Gans (Mannheim)

Johannes Huinink (Bremen)

Michaela Kreyenfeld (Rostock)

Marc Luy (Wien)

Clara H. Mulder (Groningen)

Notburga Ott (Bochum)

Peter Preisendörfer (Mainz)

Zsolt Spéder (Budapest)
Board of Reviewers / Gutachterbeirat Martin Abraham (Erlangen)

Laura Bernardi (Lausanne)

Hansjörg Bucher (Bonn)

Claudia Diehl (Konstanz)

Andreas Diekmann (Zürich)

Gabriele Doblhammer-Reiter (Rostock)

Jürgen Dorbritz (Wiesbaden)

Anette Eva Fasang (Berlin)

E.-Jürgen Flöthmann (Bielefeld)

Alexia Fürnkranz-Prskawetz (Wien)

Beat Fux (Salzburg)

Joshua Goldstein (Berkeley)

Karsten Hank (Köln)

Sonja Haug (Regensburg)

Hill Kulu (Liverpool)

Aart C. Liefbroer (Den Haag)

Kurt Lüscher (Konstanz)

Emma Lundholm (Umeå)

Nadja Milewski (Rostock)

Dimiter Philipov (Wien)

Roland Rau (Rostock)

Tomáš Sobotka (Wien)

Jeroen Spijker (Barcelona)

Olivier Thévenon (Paris)

Helga de Valk (Brussel)

Heike Trappe (Rostock)

Michael Wagner (Köln) 